\title{
Innovative Aspects in the System of Labor Relations of a Modern Enterprise
}

\author{
Fatima Kutsulova ${ }^{1}$, Saidat Nazhmutdinova ${ }^{1}$, Marianna Ostankovskaya ${ }^{1}$, Maryam \\ Umavova $^{1}$
}

\begin{abstract}
${ }^{1}$ Dagestan State University, Russia
*Email:21011979abc@gmail.com
\end{abstract}

\begin{abstract}
The article is devoted to the problems of innovation implementation in a modern enterprise. The article reflects human resources' effective use in the conditions of instability of the external environment and personnel's irrational behaviour. The paper offers some psychological tools and principles of modern personnel policy of innovation implementation at the enterprise. The article proposes to use a new wage system based on the model of competencies with specific indicators of manifestation in professional activity, as a means of material stimulation of innovative activity at the enterprise. To effectively introduce innovations at the enterprise, the article suggests several areas of personnel work with personnel: training seminars on revealing to personnel the validity and practicality of innovative transformations taking place at the enterprise; identification of innovative generators among the staff, mentors who have an active, innovative work position, can promote the ideas of new innovative competencies, etc. The study results can be used by managers and employees of the HR management Department in practice when developing strategic and tactical measures for implementing and stimulating innovative processes at the enterprise.
\end{abstract}

Keywords: Innovations, Personnel policy, Human resource, Innovative competencies, Innovative management, Labor stimulation, Enterprise communication channels.

\section{INTRODUCTION}

Nowadays, entrepreneurship is not focused on updating and modernising approaches and ways of implementing its activities. It is aimed at extreme adaptation to new economic conditions in the context of a pandemic. Maintaining existing market positions becomes a super-task, often burdened by irrational entrepreneurial behaviour in personnel management. Meanwhile, in these conditions, the presence of negative external environment factors, personnel policy, focused on innovative fields of action and innovation can bring business activities to a new level of functioning, forming a strong basis for further development.

The human resource of the enterprise, more than all available, can be a driving force capable of changing the current unstable situation in the business environment burdened by the novel coronavirus Covid-19 pandemic.

\section{RESEARCH METHODOLOGY}

In the research, scientific methods of cognition were used: synthesis, induction, analogies, deduction. The study's theoretical basis was made up of works on personnel management and innovation at the enterprise by foreign and domestic authors: Lencioni P. [1], Schwartz T., Gomez J., McCarthy K. [2], Kozhevnikova T. [3], Ivanova S. [4] and others.

\section{MAIN CONTENT}

There are often situations in Russian entrepreneurship when profitability reserves lie on the surface, and the passivity of personnel or management systems are constraining factors for business growth and development. The personnel's performance with the required quality of performance is not enough and does not fully guarantee the enterprise's effective operation. 
"An important factor in the enterprise's success is the effective use of human resources, which consists of creating an integrated environment for personnel to realise their personal and professional potential" [5].

Nowadays, every aspect of a managerial personnel decision should encourage staff to change their work behaviour to adopt innovative policies and innovative guidelines for their activities.

Current personnel policy should be based on cognitivism, namely the use of mechanisms and levers of influence based on stimulating personnel's mental activity, their acceptance of innovations and innovations in their daily activities, and their initiation. It is important to encourage staff to change their behaviour without setting any irrational restrictions on the possibility of optimal choice of methods and labor implementation methods.

The application of cognitivism principles in the economic sphere was revealed in their works by researchers Sylvestrov S.N., Bauer V.P., Eremin V.V., Pobyvaev S.A.: "From the point of view of the analysed person, it behaves rationally. But this rationality is such only in the first approximation. An example of the gap of the rationality of the first kind in cognitivism is the fear of innovation. The idea is clear, the need for its implementation is even more clear, but no real action is being taken to implement the idea" [6].

The formation of a psychological attitude by HR management - an innovation-oriented "image of the future" of the enterprise - can eliminate personnel's irrational behaviour.

The organisational part of the "image of the future" formation - innovation-oriented prospects for the enterprise development, can be associated with the prescribing of new rules of labor relations, where innovations will be associated not only with the interests of management but also with the interests of personnel at any level.

It is essential to focus on the unifying, innovative idea of enterprise development, on the complex of positive, spiritual and material benefits achieved by all.

Modernisation of labor relations and personnel work at the enterprise should be a continuous economically justified, divided into phases and stages, process of development, implementation, dissemination of innovative activity guidelines approved in specific instructions, and psychological conditions for joint work management and personnel.

Along with the use of psychological tools for forming a single mission and personnel's fate with the enterprise, we can talk about creating a new system of remuneration. For example, developing and implementing a wage system is based on the Competency Model's fixation.
"The competence model is a list of competencies with specific indicators of their manifestation in professional activity" [7].

In this case, the Model of Innovative Competencies' content can include such categories of competencies as innovative business management, innovation in production, innovation in marketing and promotion of goods, logistics innovation, innovative design, the innovation of the service and maintenance system, etc.

The new remuneration system's essence will be expressed in linking a staff unit's salary to the implementation of innovative competence: to a specific contribution to the enterprise's innovative development.

The premium for the idea and implementation of innovations, namely, an increase in earnings due to innovative competencies, can significantly activate innovative enterprise processes. It should be considered that the involvement of personnel in the process of implementing innovative competencies at the initial stages can be associated with certain costs for training and professional development of employees.

In general, the formation of the innovative enterprise activity should be carried out using complex, motivational mechanisms that significantly increase the potential performance of employees, as well as eventually form a logical sequence of innovative activity of personnel: adoption of innovations, involvement in innovative processes at the enterprise, initiation of innovations (figure 1).

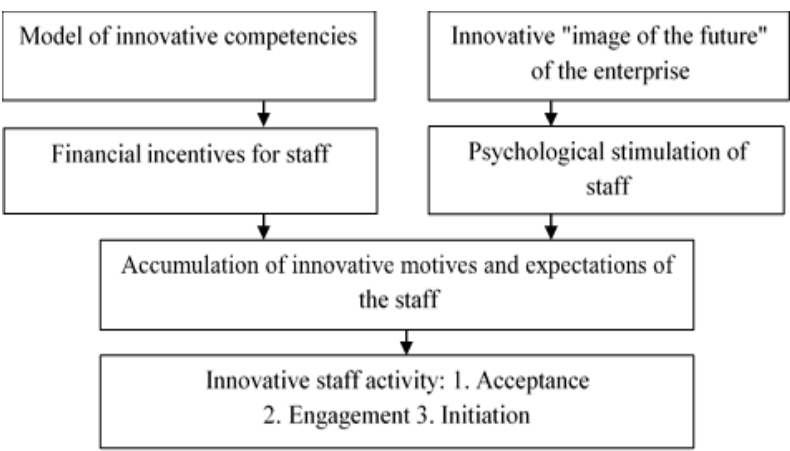

Figure 1 Formation of innovative activity of personnel at the enterprise (personnel management).

Regular training seminars on improving the innovative competencies of personnel can contribute to the enterprise's innovative transformation.

The communicative guidelines of training seminars should be based on innovations at the enterprise are not one-time actions, but everyday work requiring the staff not to adapt, but to engage actively and integrate into the ongoing processes.

The task of training seminars is also to reveal to the staff the logic of the validity and practicality of the innovative transformations taking place at the enterprise. 
In this issue, if we draw an analogy of an enterprise with a certain territory (locality), it is possible to use the theory of "Diffusion of Innovations" by Everett Rogers [8]. According to Rogers' theory, groups of people adopt new ideas, innovative technologies in a particular sequence, varying depending on the time resource of inclusion in the innovation process.

"Based on combining the criteria of time and "depth" of innovation adoption, Rogers identified different categories of adopters (or followers) of innovation, identifying five categories: innovators, early adopters, early majority, later majority and "oafs"" [9].

The last two categories of people, according to Rogers, slow down innovation processes, delaying the period of adoption and use of innovative mechanisms of activity.

However, suppose the task of accelerating innovation is problematic on a regional scale, since it is overgrown with many constraints, on an enterprise scale, by management departments' forces. In that case, this task is quite feasible: almost every modern enterprise can find creatively gifted individuals who can act as generators of innovative competencies, be mentors of innovative development of all personnel.

Highly mobile professionals with an active, innovative work position, using various communication channels, can successfully promote and promote the ideas of new innovative competencies, thereby creating a territory with a stable, innovative climate, focused on continuous growth and development.

The main tool for implementing innovations in the enterprise, in this case, will be the optimal personnel policy for stimulating innovation, based on active promotion of achieving the overall goal of developing and motivating the actions of a specific individual - a personnel unit.

The communication channel - "innovation management - innovation - personnel - innovation" should promote the ideas of collective joint innovative solutions, both in terms of methods and guidelines of the enterprise's activities.

It is essential to convey to employees that the enterprise's competitiveness in the conditions of activity burdened by the pandemic depends primarily on the staff's cohesive innovative actions.

Nadeina E.A., a modern economist - researcher of the viability of the management system, on this occasion notes: "The competitive enterprise makes its potential, which is determined by the unique resources available to it (especially human resources), which create a unique climate in the company (team, innovative, entrepreneurial), contributing to its successful functioning through the prism of continuous improvement of products and business processes and ensuring the long-term competitive advantages of the company" [10].

In general, the fundamental core principles of the presentation and organisation of the communication channel "innovation - management - innovation personnel - innovation" can be designated as:

- apparent reasonableness of innovative goals, innovations in the areas of activity of the enterprise;

- realism in assessing the ability of personnel to perform innovative tasks with existing equipment of the required quality of products (services) in the current market conditions;

- analysis of the innovative status of personnel, both in general and by departments and labor units;

- active on the scale and psychological pressure designation of innovations as the basis of competitiveness and sustainability of functioning in the market;

- the logical sequence of management decisions in the implementation of innovative projects (countering turbulence and chaotic management decisions);

- balanced management decisions: economic and social performance.

In the introducing innovations at the enterprise problem, it is necessary to draw a clear relationship between the expansion of innovation activity and productivity growth. The issues of the impact of innovative activity of the enterprise on productivity were actively considered by French researchers Crépon, Duguet et al. (1998) [11] which are now supplemented by new presentation accents and implementation tools.

"The authors have developed a CDM model that considers three main stages of the innovation process: decision-making on investing in Research and Advanced Development, innovation and productivity. At the first stage, the main factors of Research and Advanced Development are, to a greater extent, the individual characteristics of firms and market conditions. At the second stage, the authors assess the innovative result's dependence (the number of patents per 1 employee and the share of innovative sales) on the Research and Advanced Development invested at the previous stage. The third stage examines the relationship between innovation and productivity (logarithm of value-added per employee) [12].

The authors' CDM model is one of the most popular and used methods for analysing innovation activity in a modern enterprise. Applicable to the model of innovation-oriented competencies presented by us, all the stages proposed by our French colleagues can be supplemented with a new category - innovative competencies. 
"Approaches to modelling the innovation process require careful development of a model of innovation policy and a strategy for its implementation as an object of management and a means of long-term development of production in different periods. A comprehensive innovation process at a manufacturing enterprise will allow us to assess the market, scientific, technical, production and financial prospects of innovation" [13].

The dominant importance and role in the innovation process modelling, at the enterprise and the economy, of course, belongs to the state. Here we should talk about the active interaction of the main tools and levers of developing the "state-business" innovation system.

According to modern economists-researchers: "The state's main task is to ensure business and employees' interest in modernisation. This will allow "modernisation from above" to rely on "modernisation from below"" [14].

From these positions, the state, using the functionality of tax and credit regulators, can pursue a policy of stimulating innovation processes and developing the labor potential of regions in such a way that entrepreneurship is actively involved in constructive innovation processes, first of all, modernising the system of labor relations at the enterprise.

\section{CONCLUSIONS}

- innovative business guidelines and human resources management tools to stimulate innovation can bring the business structure to a new qualitative level of functioning, including in the context of the Covid-19 pandemic;

- the principles of cognitivism of personnel policy, namely the use of mechanisms and levers of influence based on stimulating the mental activity of personnel, their acceptance of innovations and innovations in their daily activities, as well as their initiation, should undoubtedly be contained in the system of relations between management and personnel of a modern enterprise;

— innovative guidelines for entrepreneurship should be based on the development of a large-scale meaningful program of psychological attitudes that increase the motivation of personnel to change in the enterprise;

- the formation of the psychological attitude of the "image of the future enterprise", the idea of common positive expectations of management and staff, will contribute to the elimination of irrational behaviour of personnel, namely, resistance to innovative processes in the enterprise;

- remuneration of labor of a modern organisation should be carried out in proportion to the contribution of personnel to innovative processes in the enterprise (the main task of the management system in this matter is to make remuneration directly dependent on the quality and quantity of innovative competencies implemented by personnel);

- transparency of information about the logic and validity of innovations implemented by management is the main factor in the successful implementation of innovative competencies by personnel;

- training seminars on improving the innovative competencies of personnel should convey that innovations in the enterprise are not one-time actions, but everyday work that requires the staff not to adapt, but to engage actively;

- according to the authors, it is advisable to supplement the CDM model developed by French researchers Crépon, Duguet with the category innovative competencies.

\section{REFERENCES}

[1] P. Lencioni, "Why people don't like to go to work. The Truth About Employee Engagement" Mann, Ivanov and Ferber Publishing House, 2017.

[2] T. Schwartz, J. Gomez, K. McCarthy, "The way we work doesn't work. Proven methods to manage life energy, Publishing house Alpina publisher, 2018.

[3] T. Kozhevnikova, "HR - as it is", Eksmo Publishing House, 2017.

[4] S. Ivanova, "Motivation 100\%, Where is the button?" Publishing house Alpina publisher, 2018.

[5] G.N. Larionova, I.V. Bagaeva, Analysis and evaluation of personnel potential of the enterprise of PJSC NIZHNEKAMSKNEFTEKHIM of the Republic of Tatarstan, Journal of Economic policy and practice 2 (2019) 34.

[6] S.N. Sylvestrov, V.P. Bauer, V.V. Eremin, S.A. Pobyvaev, Managing the Regional economy in the context of rationality gaps, Economy of the region Vol. 15 Iss. 2 (2019) 324-336. DOI: https://doi.org/10.17059/2019-2-2

[7] M.M. Lukina, Formation of a specialist's competence profile in the IT industry, M.M. Lukina, Global scientific Potential. Economics and Management 6 (2017) 32-36.

ISSN 1997-9355 Impact factor RSCI 0.510 The journal "Global Scientific Potential" is included in the list of the HAC leading peer-reviewed scientific journals and publications in which the main scientific results of the dissertation for the degree of doctor and candidate of Sciences should be published. Retrieved from: http://globaljournals.ru 
[8] E.M. Rogers, Diffusion of Innovations, New York: The Free Press, 1962, 367 p.

[9] A.S. Strekalova, Perception of innovations in territory marketing: the role of stakeholder communities, Journal of Economic Theory Vol. 16 Iss. 2 (2019) 293-304. DOI: https://doi.org/10.31063/2073-6517/2019.16-2.10

[10] E.A. Nadeina, Solvency of the management system as a factor of enterprise competitiveness // Journal of Economic Theory Vol. 16 Iss. 4 (2019) 856-861. DOI: https://doi.org/10.31063/2073-6517/2019.16$\underline{4.22}$

[11] B. Crépon, E. Duguet, J. Mairesse, Research Investment, Innovation and Productivity: An Econometric Analysis at the Firm Level, Economics of Innovation and New Technology 7(2) (1998) $115-158$.

[12] K.M. Nagieva, Influence of innovative activity on enterprises' productivity in countries with transition economies, Journal of Economic Theory Vol. 16 Iss. 3 (2019) 587-592.

[13] V.V. Gaydarova, Innovations in industrial enterprises, International scientific journal "Symbol of Science" Iss. 4, 2016.

[14] V.N. Belkina, N.A. Belkina, O.A. Antonova, "Modernisation of labour relations at Russian enterprises", Chelyabinsk State University Bulletin, Economic Sciences 60 (2018) 78. 